\title{
Candida albicans endophthalmitis following penetrating keratoplasty: A case report
}

Shahram Bamdad ${ }^{1}$, Aidin Meshksar ${ }^{2}$, Mohammad Mostafa Safarpour ${ }^{2}$

${ }^{1}$ M.D., Assistant Professor, Poostchi Eye Research Center, Department of Ophthalmology, School of Medicine, Shiraz University of Medical Sciences, Shiraz, Iran

${ }^{2}$ M.D., Poostchi Eye Research Center, Department of Ophthalmology, School of Medicine, Shiraz University of Medical Sciences, Shiraz, Iran

Type of article: Case report

\begin{abstract}
Endophthalmitis is one of the most serious complications of intraocular surgeries, and Candida albicans constitutes the majority of cases of post penetrating keratoplasty (PK) endophthalmitis. The presenting case is a 21-year-old woman with known case of advanced keratoconus and vernal keratoconjunctivitis who underwent PK, and developed recalcitrant anterior uveitis and subsequent whitish lesion on the superonasal of the lens. She was on topical steroids with possible impression of Uretts Zavalia syndrome versus phacoantigenic uveitis following traumatic cataract up to the $50^{\text {th }}$ day of post operation that manifested symptoms of frank endophthalmitis; and underwent deep vitrectomy, lensectomy, localized iridectomy and irrigation with diluted Imipenem and Amphotericin-B. Microbiologic study of a vitreous sample revealed growth of Candida albicans, however optisol culture was negative and donor rim was not evaluated. One week later, intravitreal Amphotericin-B was administered. The patient remained aphakic with clear graft in the $6^{\text {th }}$ month follow up. Due to great correlation of positive donor rim culture with fungal endophthalmitis and the devastating effect of delayed diagnosis, routine donor rim culture is recommended, to aid us in earlier diagnosis in the presence of nonspecific early signs of fungal endophthalmitis.
\end{abstract}

Keywords: Endophthalmitis, Keratoplasty, Candida

\section{Introduction}

Post operation endophthalmitis, although uncommon, is one of the most devastating complications of penetrating keratoplasty (PK). The recent increase in the incidence of exogenous fungal endophthalmitis is partly due to frequent steroid use (1), and broad spectrum antibiotic usage which are both usual in the post-operative care of these patients $(2,3)$. Also, contaminated corneal graft or preservation medium play a major role in post operation fungal endophthalmitis (4-7). Molds, especially Candida albicans is the most common fungal cause and is almost always due to contaminated donor graft in patients who had undergone PK, and there is an extensive concordance between positive rim culture and fungal endophthalmitis $(4,8,9)$. There are only a few reports of post PK Candida endophthalmitis with negative donor rim culture $(3,10,11)$. Fungal endophthalmitis usually has an insidious and refractory course, and early on in the course, may be mistaken for other postoperative complications, and results in delayed diagnosis which further compromise the patients visual acuity $(4,9,10)$. Here, we are going to present an unusual case of post PK Candida albicans endophthalmitis who had positive vitreous culture while the optisol culture was negative. This study shows that routine donor rim culture is necessary and even in the absence of classic findings of fungal endophthalmitis, it should be suspected in any case of post PK who present with retractable uveitis.

\section{Corresponding author:}

Dr Aidin Meshksar, Poostchi Eye Research Center, Department of Ophthalmology, School of Medicine, Shiraz University of Medical Sciences, Shiraz, Iran.

Tel:+987132302830,Email: Meshksaray@sums.ac.ir, and Meshksarai@gmail.com

Received: February 10, 2017, Accepted: December 24, 2017, Published: January 2018

iThenticate screening: September 12, 2017, English editing: December 28, 2017, Quality control: January 12, 2018

This article has been reviewed / commented by three experts

(C) 2018 The Authors. This is an open access article under the terms of the Creative Commons Attribution-NonCommercialNoDerivs License, which permits use and distribution in any medium, provided the original work is properly cited, the use is non-commercial and no modifications or adaptations are made. 


\section{Case presentation}

\subsection{Patient information, history, and clinical findings}

A 21-year-old woman with known case of advanced keratoconus, who was intolerable of rigid gas permeable contact lens due to vernal keratoconjunctivitis $(\mathrm{VKC})$, came with a chief complaint of decreased visual acuity in the left eye. She had Deep Anterior Lamellar Keratoplasty (DALK) of the right eye due to keratoconus approximately 5 years previously. She had Best Corrected Visual Acuity (BCVA) of 20/100. The cornea was clear and a fundoscopic exam was unremarkable. Regarding her past medical history, she underwent an uneventful penetrating keratoplasty (PK) of the left eye in June 2015 at Shiraz, Khalili hospital. She was on topical Ciprofloxacin 3\% and Betamethasone $1 \%$ every 6 hours postoperatively.

\subsection{Diagnostic Assessment}

The graft was unremarkable until 5th day post operation while she presented with 2 plus conjunctival injections and 2 plus anterior cell reaction (ACR). On slit lamp examination, the cornea was clear and there was no infiltration. Due to anterior uveitis, topical betamethasone was applied more frequently every 2 hours with possible impression of Urrets Zavalia syndrome. She had substantial improvement in symptoms, and ACR was decreased to trace amounts on the 10th day of post operation. At the same time a whitish lesion became apparent on the superonasal of the lens, underneath the iris sphincter with localized posterior synechia which was perceived to be a localized cataract due to possible intraoperative trauma to the lens (Figure 1). So the possibility of phacoantigenic uveitis was also considered. By gradually tapering the steroid in 2 weeks, the symptoms recurred and there was diffuse fine keratic precipitates (KP), so again steroids were applied more frequently and tapered as the ACR was decreased. This cycle was repeated until the $50^{\text {th }}$ day post operation that showed evidence of mutton fat KPs with fibrinous reaction in the anterior chamber.

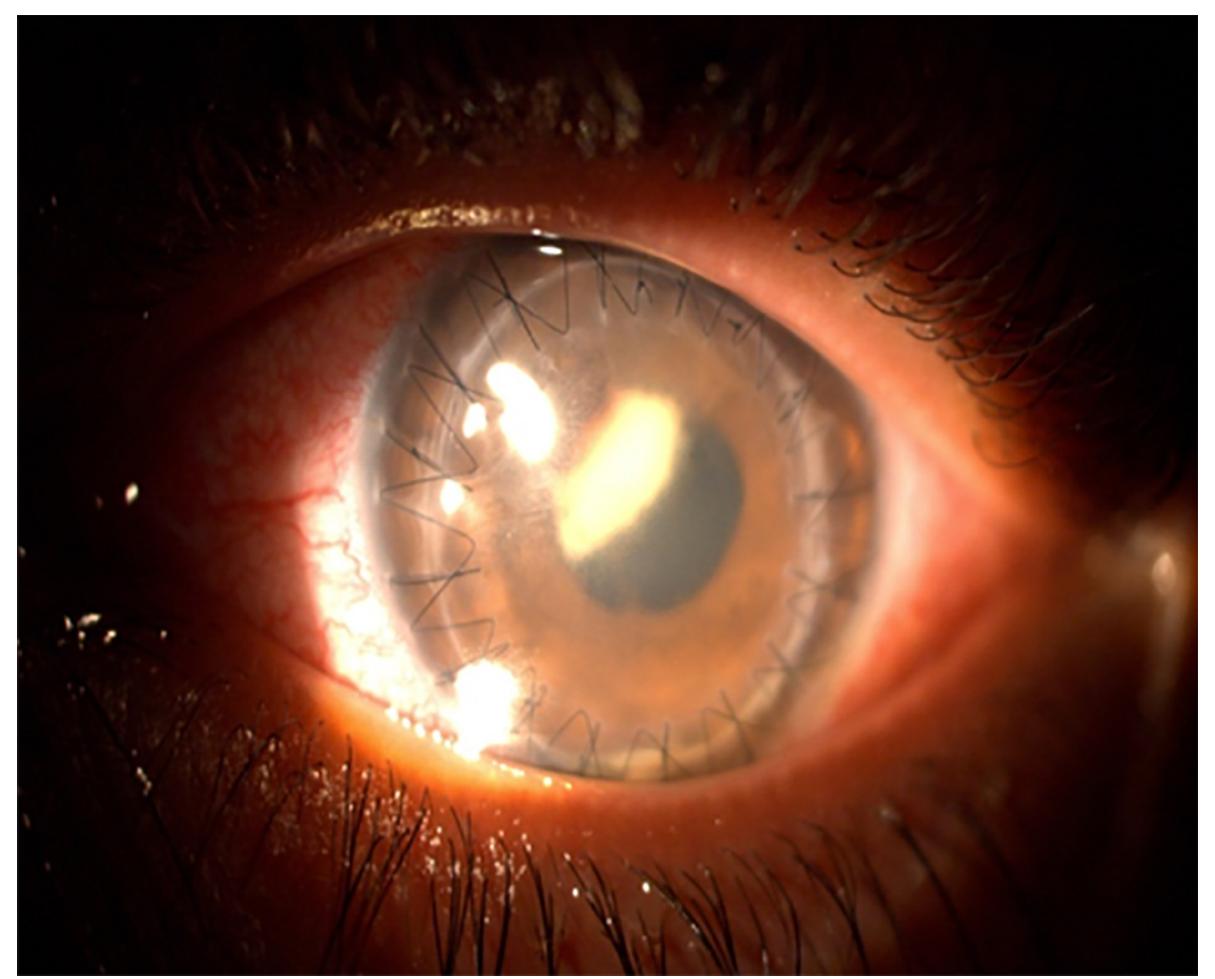

Figure 1. Post PK Candida Albicans infiltration of the anterior chamber with localized posterior synechiae

\subsection{Therapeutic Intervention}

She was admitted to the ophthalmology ward of Khalili Hospital with clinical impression of possible post operation fungal endophthalmitis. On ocular sonography, she had moderate to severe vitreous opacity in favor of inflammation or endophthalmitis. So, deep vitrectomy, lensectomy and localized iridectomy (due to severe adhesion of iris to lens) was done, and irrigation with diluted Imipenem and Amphotericin was applied, and samples were sent for microbiologic studies. She was given intravenous Vancomycin 1 gr every 12 hours, intravenous Ceftazidime 1 gr every 8 hours, Fluconazole $200 \mathrm{mg}$ tablet every 12 hours, Prednisolone $50 \mathrm{mg}$ tablet every day, Gemifloxacin 320 
mg tablet every day, topical Levofloxacin every 2 hours, topical Prednisolone 1\% every 6 hours and topical Atropine $1 \%$ every 6 hours. Visual acuity was Light Perception, and on slit lamp examination there was a moderate conjunctival injection. The graft was clear with intact sutures, the anterior chamber was deep and there was a moderate fibrinous reaction. Anterior vitreous and fundus were not visible. Microbiologic studies of vitreous samples revealed growth of Candida albicans. Optisol culture was negative, but donor rim was not evaluated microbiologically. Due to lack of improvement of fibrinous reaction and Candida growth on culture media, intravitreal injection of Amphotericin-B and Ceftazidime was administered 7 days later.

\subsection{Follow-up and Outcomes}

Fibrinous reaction was resolved within a few days and the ocular exam became unremarkable after 2 weeks. The patient is aphakic and has vision of 2 meters' finger count and clear graft.

\section{Discussion}

Endophthalmitis is one of the most devastating and debilitating complications of intraocular surgeries. The prevalence of post PK endophthalmitis is $0.108 \%$ to $0.5 \%$. Post-operative infection is most commonly caused by organisms like Staphylococcus aureus, Streptococcus species and fungi (esp. Candida). Candida species especially Candida albicans is responsible for the vast majority of post PK endophthalmitis. Candida is responsible for about $15 \%$ to $20 \%$ of endophthalmitis cases reported to the Eye Bank Association of America (EBAA), and is emerging as one of the most common serious complications of penetrating keratoplasty (5). There are three possible sources of fungal endophthalmitis including patients flora, contaminated solution and donor graft (10). Although fungi are not considered as normal flora of the ocular surface, they have been isolated from conjunctiva of $28 \%$ of healthy individuals and $2.5 \%$ to $6.5 \%$ of donor corneoscleral rims. It increases with ocular surface disease and environments suitable for their growth such as chronic steroid or antibiotic use, which was present in our case due to VKC. However, it is not established whether this can contribute to postoperative infections. Nearly all cases of post PK fungal endophthalmitis are caused by the contaminated donor $(5,6,8)$. However, there are few reports of cases with negative rim culture in the literature $(3,10,11)$. The incidence of fungal contamination of donor rim is rare $(0-12 \%)$ but the rate of corresponding endophthalmitis and keratitis is high $(5-12 \%)$. So routine rim culture can be beneficial in early detection of post PK fungal endophthalmitis, however, it was not accomplished in our case. Some authors consider prophylactic antifungal treatment in the setting of positive rim culture, but due to the potential for local and systemic side effects, others prefer to closely observe these patients. Fungal keratitis or endophthalmitis usually occur between 1 to 4 weeks post operation $(4,8,12,13)$, as it was in our case who presented on the 5th post operation day. Clinical manifestations of fungal endophthalmitis include late onset whitish endothelial plaque, ACR, hypopyon and vitreous involvement $(6,11,13,14)$. However, our case presented with refractory uveitis and subsequent whitish lesion between iris and lens which was misleading. Antifungal therapy combined with vitrectomy is the suitable treatment. Administration of Amphotericin-B is the corner stone of intravitreal therapy. To treat infections that involve the cornea, sclera or anterior chamber, topical or periocular antifungal agents are useful. Also, the Azoles derivatives are successfully used in treatment of severe ocular fungal infections including candida $(1,15)$. In our study, the patient developed insidiously with recurrent anterior uveitis in the 1st week post operation which was aggravated with tapering of steroid and gradually, she showed clinical features more suggestive of a serious underlying cause. Late clinical features and microbiologic evaluation guided us towards the underlying fungal infection. In this case, the possibility of phacoantigenic uveitis versus Urrets Zavalia syndrome and negative optisol culture, resulted in delayed diagnosis; however, if donor rim culture had been checked as a routine, it would have resulted in earlier detection and intervention and possibly, more favorable results.

\section{Conclusions}

Candida albicans is a rare cause of post operation endophthalmitis and due to the insidious course of fungal endophthalmitis it can be misleading in the absence of microbiologic evidence. In the recent past, studies of nearly all post PK fungal endophthalmitis patients had a positive rim culture for the corresponding organism, however, here we presented a case of post PK Candida albicans endophthalmitis who was diagnosed clinically in the absence of microbiologic study of donor rim. Due to great correlation of positive donor rim culture with fungal endophthalmitis and the devastating effect of delayed diagnosis, it is wise to conduct donor rim culture routinely, to aid us in earlier diagnosis in the presence of nonspecific early signs of fungal endophthalmitis which occurs insidiously, and can be misleading. 


\section{Acknowledgments:}

This case was supported by Poostchi Eye Research Center, Department of Ophthalmology, School of Medicine, Shiraz University of Medical Sciences, Shiraz, Iran. We would like to acknowledge the patient who kindly agreed for her case to be written up.

\section{Conflict of Interest:}

There is no conflict of interest to be declared.

Authors' contributions:

All authors contributed to this project and article equally. All authors read and approved the final manuscript.

\section{References:}

1) Wykoff CC, Flynn HW, Miller D, Scott IU, Alfonso EC. Exogenous fungal endophthalmitis: microbiology and clinical outcomes. Ophthalmology. 2008; 115(9): 1501-7. e2. doi: 10.1016/j.ophtha.2008.02.027. PMID: 18486220.

2) Fong LP, Gladstone D, Casey T. Corneo-scleral rim cultures: donor contamination a case of fungal endophthalmitis transmitted by K-Sol stored cornea. Eye. 1988; 2(6): 670-6. doi: 10.1038/eye.1988.123. PMID: 3151485.

3) Gupta MK. Candida albicans isolated from post-operative penetrating keratoplasty patient: Case report. Asian Journal of Medical Sciences. 2014; 5(3): 116-9.

4) Caldwell MC, Perfect JR, Carlson AN, Proia AD. Candida glabrata endophthalmitis following penetrating keratoplasty. J Cataract Refract Surg. 2009; 35(3): 598-602. doi: 10.1016/j.jcrs.2008.08.046. PMID: 19251157.

5) Merchant A, Zacks CM, Wilhelmus K, Durand M, Dohlman CH. Candidal endophthalmitis after keratoplasty. Cornea. 2001; 20(2): 226-9. doi: 10.1097/00003226-200103000-00026. PMID: 11248837.

6) Sutphin JE, Pfaller MA, Hollis RJ, Wagoner MD. Donor-to-host transmission of Candida albicans after corneal transplantation. American journal of ophthalmology. 2002; 134(1): 120-1. doi: 10.1016/S00029394(02)01427-7.

7) Cameron JA, Antonios SR, Cotter JB, Habash NR. Endophthalmitis from contaminated donor corneas following penetrating keratoplasty. Archives of ophthalmology. 1991; 109(1): 54-9. doi: 10.1001/archopht.1991.01080010056032. PMID: 1987949.

8) Keyhani K, Seedor JA, Shah MK, Terraciano AJ, Ritterband DC. The incidence of fungal keratitis and endophthalmitis following penetrating keratoplasty. Cornea. 2005; 24(3): 288-91. doi: 10.1097/01.ico..0000138832.3486.70. PMID: 15778600.

9) Foroutan A, Afsar N, Rezaei-Kanavi M. Late-Onset Candida glabrata Endophthalmitis Following Deep Anterior Lamellar Keratoplasty: A Case Report. Iranian Journal of Ophthalmology. 2007; 19(4): 48-51.

10) Schotveld JH, Raijmakers AJ, Henry Y, Zaal MJ. Donor-to-host transmitted Candida endophthalmitis after penetrating keratoplasty. Cornea. 2005; 24(7): 887-9. doi: 10.1097/01.ico.0000157403.27150.c1. PMID: 16160513.

11) Muzaliha MN, Adil H, Ibrahim M, Shatriah I. Candida glabrata endophthalmitis following penetrating keratoplasty in a patient with negative donor rim culture. BMC ophthalmology. 2010; 10(1): 18. doi: 10.1186/1471-2415-10-18. PMID: 20537193, PMCID: PMC2891680.

12) Al-Assiri A, Al-Jastaneiah S, Al-Khalaf A, Al-Fraikh H, Wagoner MD. Late-onset donor-to-host transmission of Candida glabrata following corneal transplantation. Cornea. 2006; 25(1): 123. doi: 10.1097/01.ico.0000164777.80879.07. PMID: 16331055.

13) Tappeiner C, Goldblum D, Zimmerli S, Fux C, Frueh BE. Donor-to-host transmission of Candida glabrata to both recipients of corneal transplants from the same donor. Cornea. 2009; 28(2): 228-30. doi: 10.1097/ICO.0b013e318183a3e3. PMID: 19158573.

14) Chapman FM, Orr KE, Armitage WJ, Easty DL, Cottrell DG. Candida glabrata endophthalmitis following penetrating keratoplasty. Br J Ophthalmol. 1998; 82(6): 712-3. PMID: 9797681, PMCID: PMC1722613.

15) Chowdhury T, Jalali S, Reddy KS, Sharma S. Candida Albicans endophthalmitis after phacoemulsification and intraocular lens implantation. 2003. 